\title{
Speech and language interventions for stroke-induced aphasia
}

\author{
Inger Lundeborg Hammarström ${ }^{1}$ and Christina Samuelsson ${ }^{2}$ \\ ${ }^{1}$ Linköping University, Sweden \\ ${ }^{2}$ Karolinska Institute, Stockholm, Sweden
}

\begin{abstract}
The aim of the present study was to investigate whether the use of video recordings of interactions involving persons with aphasia and speech-language pathology students enhance students' competence as conversation partners of people with communicative disabilities. A further aim was to explore the experiences and perspectives from the viewpoint of both participating students and persons with aphasia.

Six persons with aphasia met 34 speech and language pathology students in pairs for 10 minutes of conversation. The video recordings were transcribed, in order to identify phenomena influencing the interaction. The students answered a questionnaire about the assignment. A semi-structured group interview with the aphasic individuals was conducted.

The analyses of the conversations and the answers to the questionnaire revealed that the students gained important knowledge both on how aphasia may affect and limit aphasic individuals' communicative activity and participation, and hands-on insights into how different interactional strategies may enhance aphasic individuals' possibilities in interaction, but also highlighting behaviors that may be less beneficial. The persons with aphasia perceived the activity as important and rewarding.

The results demonstrate the benefits of involving patients in health education and the students' use of video recordings, transcriptions, and subsequent analysis.
\end{abstract}

KeYWORdS: PERSONS WITH APHASIA (PWAs), INTERACTION, SLP STUDENTS

\footnotetext{
$\overline{\text { Affiliations }}$

'Linköping University, Sweden

${ }^{2}$ Karolinska Institute, Stockholm, Sweden

Email: christina.samuelsson@ki.se (corresponding author)
} 


\section{Introduction}

Worldwide, many individuals suffer from stroke annually. The incidence per 100,000 population ranges from about 70 to 200 cases in high-income countries (Thrift et al., 2017). About a third of all stroke survivors are estimated to have aphasia, which has a profound effect on the lives of affected persons. Difficulties that persons with aphasia (PWAs) experience relating to disruptions in freeflowing verbal exchange with conversation partners put daily limitations on communicative activity and participation. Speech and language intervention for PWAs should therefore be focused on strategies to enhance communicative participation, and it has been shown that they are able to participate more efficiently in communication when communication partners are trained to facilitate the PWAs' everyday social interactions (Cherney, Simmons-Mackie, Raymer, Armstrong, and Holland, 2013; Eriksson, 2015). In national clinical guidelines for stroke in Sweden and in the United Kingdom, communication partner training is recommended, and the need to facilitate opportunities for community activities and support is stressed (https://www.socialstyrelsen.se/globalassets/ sharepoint-dokument/artikelkatalog/nationella-riktlinjer/2020-1-6545.pdf; Intercollegiate Stroke Working Party, 2012).

Traditionally, aphasia intervention has been symptom based, with the goal of improving PWAs' linguistic abilities by focusing on the areas that they have particular difficulties with (Basso, 2003; Plejert, Samuelsson, and Anward, 2016). In the past few decades, there has been a growing trend in aphasia intervention to focus more on communicative participation in family as well as community contexts (Horton, Lane, and Shiggins, 2016). In a survey of the goals of rehabilitation for PWAs, it was demonstrated that the majority of goals for patients and their family members could be linked to activities and participation (Wallace et al., 2017b). This was also true for clinicians and managers within aphasia care (Wallace, Worrall, Rose, and Le Dorze 2017a). By providing supported communication with skilled communication partners and appropriate communicative support, it has been shown that communicative participation is enhanced (Kagan, Black, Duchan, Simmons-Mackie, and Square, 2001). An underlying principle of supported communication is that communication is a collaborative and co-constructed act with a shared responsibility between the unimpaired communication partner and the person with aphasia regarding the exchange of information and communicative participation (Kagan et al., 2001).

Education and skills training for speech-language pathology students focusing on their ability to acknowledge and reveal the competence of PWAs must therefore be an essential part of their studies. One way of doing this is to involve PWAs as trainers in Conversation Partner Schemes. Conversation 
Partner Schemes were developed by McVicker and co-workers (McVicker, Parr, Pound, and Duchan, 2009) in London and used in a project with interaction between PWAs and matched volunteer conversation partners. Conversation Partner Schemes are premised on the social model of disability used in aphasiology, in which people with disabilities are considered to be experts in their own condition (Byng and Felson Duchan, 2005). The volunteers visited PWAs for one hour weekly during a six-month period. A project manager in charge of the scheme recruited and trained the volunteers, and also provided support and supervision during the six-month period. At the end of the period, an evaluative questionnaire was distributed to the participating parties. Eighty percent of the PWAs reported that they felt a real change in their confidence, and almost all volunteers said that they enjoyed visiting the PWAs, and that they found interesting things to talk about (McVicker et al., 2009). The effects of communication partner training on the communication skills of speech-language pathology (SLP) students were examined in a study in Australia (Finch et al., 2017). Two groups of students participated and were divided into two groups. One group received a lecture about communication strategies useful in conversation with PWAs, and then participated in conversation with PWAs, whereas the other group participated in the conversation with PWAs without receiving the lecture. The group who received the lecture scored significantly better on measures of skills in supported conversation, measures of participation, types of strategies, and on occurrence of repairs of conversation breakdowns, in comparison to the group who did not receive the lecture. The first group also introduced more new ideas into the conversations (Finch et al., 2017).

At the University of East Anglia (United Kingdom), Conversation Partner Schemes are implemented as a compulsory element at the beginning and toward the end of the undergraduate speech and language pathology education program. Inspired by the Conversation Partner Schemes in the SLP educational program at the University of East Anglia, a similar element with video recordings of conversations between PWAs and students was introduced during the first academic year in the speech and language pathology program at Linköping University (Sweden). A conversation analytic approach was adopted within this Conversation Partner Scheme, and all conversations were video-recorded. The rationale for this approach was to fulfil the twofold aim of the study: to increase students' readiness to meet persons with communicative disabilities, and to raise awareness of the students' individual contributions during interaction. The emic stance taken within conversation analysis (Sidnell, 2012) influenced how the recordings were analyzed. Conversation analysis informed the present study in terms of being driven by unmotivated looking, and the analysis did not at all focus on identifying 
symptoms of aphasia or on evaluating students' performance in terms of correct or incorrect; rather, the focus was on identifying interactional behaviors.

The twofold aim of the project is to target both students' readiness to meet PWAs and also to serve the purpose of raising students' awareness of interactional phenomena. These aims are met by exploring the experiences and perspectives of both participating students and expert trainers, and by analyzing the conversations between students and PWAs.

\section{Method}

The present article reports on a project where first-year speech-language pathology students had the opportunity to act as communication partners for PWAs who were trained to act within speech-language pathology education as experts by experience. Video-recording and interactional analysis, which previously has been shown to be beneficial in research on communicative disabilities (Antaki, 2011; Kagan and LeBlanc, 2002), were used in combination with questionnaires to students, and interviews with participants with aphasia. The study was carried out in accordance with the ethical principles for medical research of the Helsinki Declaration, as revised in 2008.

\section{Participants}

\section{The experts}

Six PWAs, three males and three females aged 38-86 with moderate to severe communicative difficulties, including both receptive and expressive problems, were recruited from the Swedish national aphasia association and through a speech and language pathologist working with aphasia rehabilitation. Based on recent acknowledgments that PWAs have expertise about their aphasia based on lived experience, these individuals were designated as 'experts.' The PWAs took part in a short training program run by the authors of this study. Discussions about how to carry out the activity, how to meet students, and how to engage in role-play with the students were included.

Thirty-four first-year speech and language pathology students participated as conversation partners. The choice of first-year students was motivated by an intentional focus on the conversation itself and not on the symptoms, examinations, or treatment of aphasia that are included later in the educational program. Prior to the exercise, the students attended lectures on conversation analysis and a workshop, in which they applied conversation analytic principles (Hutchby and Wooffit, 2008) and made use of a transcription key adapted 
with some modifications from Sacks, Schegloff, and Jefferson (1974); see Appendix 1.

\section{Procedure}

\section{The conversation exercises}

The students were divided into two groups scheduled for the same protocol on different days. Initially, the students received a five-minute lecture held by the second author on aphasia and its consequences on daily communication and functioning, and on common features of interaction involving PWAs. After that, the experts presented themselves. The students were then divided into eight (day 1) or nine pairs (day 2) and given a schedule telling them in which order they were to meet the experts. The student pairs were instructed that one of them should hold an everyday conversation with the expert for $10 \mathrm{~min}$ utes, and that the other student should video-record the conversation, without taking part in the conversation. After each conversation, the students received feedback from the expert. The exercise was then continued by each student pair changing roles and repeating the exercise with a new expert. In this way, each student had at least three of their own recorded conversations with different PWAs. After the exercise, the students were instructed to watch their video clips and transcribe the conversations according to conversation analytic conventions, and to reflect on their recordings. After having watched their video recordings several times, the students were asked to select a couple of key episodes demonstrating phenomena relevant for discussion around communication involving persons with communicative disabilities in general, and PWAs in particular. According to the instructions to students, it was suggested that the students should focus on behavioral patterns such as turn-taking, repair sequences, and other interactional phenomena. The selected sequences were then played to small groups of these speech-language pathology students together with the instruction to discuss similarities and differences in the sequences. The student groups were further instructed to make a choice of two video clips that shed light on common experiences and on things they wanted to discuss. They then attended a full class seminar in which they showed their clips and raised their points of discussion.

\section{The student questionnaire and the focus-group interview with the PWAs}

The students took part in an anonymous written and individual evaluation of the exercise, including both grading of different parts of the exercise and open 
questions about insights gained from watching and transcribing the video recordings.

To capture the experiences and perceptions resulting from meeting the students, the experts participated in a focus-group interview a month after they had met the students. An interview guide was designed with the questions in the students' evaluation questionnaire as background material, see Appendix 2. One of the authors acted as moderator and took down the participants' answers in writing simultaneously as the interview proceeded. At the interview, paper and pencils were available if the experts needed to write down something to support the communication. The interview lasted for approximately 90 minutes.

\section{Data analysis}

The participating students had received basic education in transcription and analysis according to conversation analytical principles and conventions (see Appendix 1), and after the session with the PWAs, the students were instructed to select sequences that they found particularly interesting, and to transcribe these sequences. The key episodes chosen by the students were analyzed by the authors of the present study, in order to identify which types of phenomena the students had chosen as relevant for discussion. Representative examples from the students' transcriptions are demonstrated and analyzed in the Results section below.

The results of the questionnaire on students' evaluations were summarized using descriptive statistics, and the transcriptions from the interview with the experts were grouped and major themes were identified by the moderator.

\section{Results}

\section{Interaction}

The analysis of the key sequences chosen by the students as 'relevant examples' demonstrated that students focused on their own interactional behavior. These key sequences also demonstrated how their behavior had an impact on the possibilities for the PWAs to contribute in the interaction; the selected examples illustrated enhancing and supportive strategies, less beneficial strategies, and the use of gestures. It was also revealed that many students had chosen sequences according to content (i.e., where the PWAs talked about living with aphasia, and about how it felt when they had their stroke). In the discussion of the results that follows, examples of students' enhancing strategies, some examples of less beneficial strategies used by students, some 
examples illustrating the use of gestures highlighted by students, and several illustrative examples of content that students considered relevant are detailed.

For each extract, a translation from Swedish into English is provided in italics below in the transcript. The translation into English attempts to preserve the spoken language and social quality of the speech. At times, this means that it is not an exact verbatim translation. As Swedish and English are reasonably similar in terms of grammar, however, only a few modifications have been made.

\section{Excerpts illustrating enhancing strategies}

The following two excerpts are examples brought to the discussion by students in order to illustrate enhancing strategies. In excerpts 1 and 2, the PWAs are talking about their problems, and the participating students enhance the communication of the PWAs using different strategies, in order to secure mutual understanding. Two strategies are described in the excerpts: requests for confirmation of understanding (Drew, 1998; Heritage, 1985; Kurhila, 2003) and a particular form of self-initiated other repair (Hutchby and Wooffitt, 2008; Schegloff, Jefferson, and Sacks, 1977).

Excerpt 1 is from a conversation between a student (S) and a person with aphasia $(\mathrm{P})$ about the problem he experienced with his wife previously interrupting him when his aphasia was worse.

\section{Excerpt 1}

51. P: det var svårt att (1.3) för henne att (0.7)

it was hard to (1.3) for her to (0.7)

52. när lå låta mig t tala mig till ill $\mathrm{s}$ slut when le let me talk me to o the end

53. S: $[m h](($ nickar $))$

[mh] ((nods))

54. P: [först]

[first]

55. S: [mh det] kan jag tänka mig [mh that] I can imagine

56. P: [aa]

57. S: det är lätt att [man fyller i]

it is easy to [you fill in]

58. P: [aa, aa, aa]

59. S: och [hjälper för mycket]

and [help too much]

60. P: [ja ja ja] ((nickar))

[yes yes yes] ((nods)) 
In this excerpt, the PWA starts by saying that it was difficult for his wife to let him finish his utterances (lines 51-52 and 54). The student confirms this and adds that she can imagine the situation (line 55). The student then expands the PWA's utterance and provides a concluding expansion of what the PWA had said, stating that it is easy to fill in (lines 57 and 59), which is vividly confirmed by the PWA (lines 58 and 60). This expansion thus serves as an indicator of the student having understood what the PWA had just said (Kurhila, 2003). This is an illustrative example of how a story was co-constructed by the PWA and the student, in order to reach mutual understanding, and it exemplifies a beneficial strategy.

Excerpt 2 illustrates how a student (S) completes the contribution of the person with aphasia $(\mathrm{P})$, which is approved, and then asks about the appropriateness of 'filling in' in interactions involving the PWAs.

\section{Excerpt 2}

21. P: logoped och ((gestikulerar)) och (.) vad är det

speech-language pathologist and ((gesticulates)) and (.) what is it

22. S: arbetsterapeut occupational therapist

23. P: JAA ((gestikulerar vinnargest))

YES ((makes a winning gesture))

24. S: $(($ nods $))$

25. P: tack tack tack

thank you thank you thank you

26. S: får man fylla $\mathrm{i}$

is it okay to fill in

27. P: jaarå

of course

28. S: ja

yes

In excerpt 2, the student comments on how the PWA feels about this strategy. Several students reported that they had been using candidate understandings, and that the watching of the video recordings had raised their awareness of this enhancing strategy.

The excerpt starts with the PWA trying unsuccessfully to come up with a word. Exhibiting difficulty, the PWA initiates repair by requesting help (line 21), whereupon the student proposes 'occupational therapist' (line 22). This is confirmed by the PWA, and he also expresses his gratitude (line 25). The student then asks whether filling in the elusive word (line 26) is acceptable, and this is also confirmed by the PWA. This excerpt demonstrates how a student may take the opportunity to learn from a PWA about beneficial strategies in 
interaction, which in turn may enhance the possibilities for PWAs to participate in social interaction.

\section{Excerpts illustrating less beneficial strategies}

The next part of the present Results section comprises two excerpts that demonstrate how less beneficial strategies may possibly aggravate the difficulties of PWAs. Examples of less beneficial strategies were highlighted by several students as something that they sometimes noticed in the actual situation. However, they also became more aware of these less beneficial strategies in particular by watching the videos. Excerpts 3 and 4 are taken from a conversation between a student $(\mathrm{S})$ and a PWA $(\mathrm{P})$ with rather severe aphasia and major expressive problems.

\section{Excerpt 3}

45. S: men annars vad tidningar (0.5) kollar du på tv eller

but else which newspapers (0.5) do you watch tv or

46. $\mathrm{P}:$ vadå

what

47. S: tv television

tv television

48. P: jaå

yeah

49. S: också okej

also ok

50. P: ((inandning)) aa

((inbreath)) aa

This excerpt starts with the student posing a rather complicated question (line 45) comprising two different elements (i.e., newspapers and television.). The PWA does not understand the question and asks for clarification (line 46), whereupon the student repeats one of the elements (line 47). However, the PWA responds in a somewhat hesitating way (line 48), which is expanded on and interpreted by the student (line 49) and only partly confirmed by the PWA (line 50). This excerpt illustrates how questions that are too complicated may hamper the involvement during an interaction for a PWA.

Excerpt 4 is from an earlier part of the same conversation as in excerpt 3 , where the student is talking to the PWA about her reading habits. The student gives a lot of information, and during the seminar she commented on her own performance as being both beneficial, since it filled the conversational space, but also as not helpful since the PWA was not given enough space in the conversation. She also expressed that her awareness was raised by watching the video recording. 


\section{Excerpt 4}

24. S: okej har du läst Agatha Christie ok have you read Agatha Christie

25. (2.0)

26. S: ehmm

27. P: för länge sen a long time ago

28. S: länge sen long ago

29. ((mutual laughter $))$

30. S: Hercule Poirot

31. P: vadå what

32. S: Hercule Poirot (1.0) Poirot

33. P: jåa? yeah

34. S: asså min mamma älskar dem then my mother loves them

35. P: jaha? ok

36. S: hon typ (0.5) hon har nästan alla she like (0.5) she has almost all

37. jag har försökt också själv (0.5) läsa dom I have tried to also myself (0.5) to read them

38. P: ja?

yes

39. S: dom e jättespännande they are super exciting

40: P: ((inandning)) aa, åå ((inbreath)) $a a$, åå

41. S: händer så mycket man vet aldrig $(0.5)$ vem $\mathrm{e}$ happens so much you never know (0.5) who is

42. P: vem

who

43. S: den som (1.0) eh (1.5) vem som har mördat nån just ((skratt)) the one (1.0) eh (1.5) who has killed someone ((laughter))

44. (1.0)

45. S: eller gjort nånting or done something

Excerpt 4 starts with the student asking the PWA if she has read an old crime novel (line 24). This is followed by a pause, a hesitation phenomenon by the student, and a surprised answer by the PWA (line 27). This response is repeated by the student, and both participants laugh (line 29). The student 
then continues talking about the books (lines 30, 32, 34, 36, 37, 39, 41, 43, and 45), and the PWA is minimally responsive, as demonstrated by the questioning intonation in the back-channeling signals (lines 33, 35, and 38), and she is not given much space in this interaction. However, this PWA has major expressive problems, and the student's contributions, giving some information about herself and her mother, also illustrate how this can keep the conversation going even if one of the participants has communicative problems.

\section{Excerpts illustrating gestural use}

The following two excerpts illustrate how gestures are used by PWAs and copied by the students. Gestural usage was highlighted by several students as a feature that was frequently employed by the PWAs, including the realization that the students also used gestures to a greater extent than they were aware of before having watched the video recordings.

Excerpt 5 is taken from a conversation between a student (S) and one of the participating PWAs $(\mathrm{P})$ at the beginning of the conversation. $\mathrm{P}$ is talking about her aphasia, and about which communicative resources she uses.

\section{Excerpt 5}

1. S: hur har det har det påverkats någonting av afasin nu how has it has it been affected in any way by the aphasia now

2. P: .hh ja jag tecknar inte [så väldigt] mycket ((knackar på bordet)) .hh yea I don't draw [so very] much ((taps on the table))

3. S: [nee: ] [noo:]

4. P: men ehh jag ku- kommunicerade med min man med but I cu-communicated with my husband with

5. [teckningar när jag eh:] ((gestikulerar med handen mot halsen)) [drawings when I eh] ((gesture with hand toward the throat))

6. S: [mmhmm innan talet kom] ((gestikulerar med handen mot halsen)) [mmhmm before the speech came] ((gesture with hand toward the throat))

Excerpt 5 starts with $\mathrm{S}$ asking a question about the aphasia (line 1), and $\mathrm{P}$ explains that she has reduced her use of drawing (line 2), and expands the utterance by adding information about how she used to communicate by drawing during the beginning stages of her aphasia (line 5). This utterance ends with a hesitation marker 'eh' in combination with a gesture toward the throat. The student responds to this with a completion of the utterance and with an imitation of the gesture (line 6). Gestures frequently co-occur with talk in ordinary conversations (Kendon, 2004). The frequent and somewhat different use of gestures by PWAs has been described in previous research (Goodwin, 2004; Sekine and Rose, 2013). In the present data, the gesture noted in conjunction 
with word-finding difficulty on the part of the PWA may be categorized as 'difficulty in verbalization,' and the mimicry seems to serve the purpose of alignment between the student and the PWA. However, as reported by several students, some of their gestures were used to enhance the understanding for the PWA, as in the following example.

Excerpt 6 is taken from a conversation between a student (S) and one of the participants with aphasia (P) about a minute into the conversation. They are talking about P's aphasia symptoms, and both participants use gestures to accompany their speech.

\section{Excerpt 6}

56. P: eh (.) inte klarat av

eh (.) not have managed

57. S: näe::

no::

58. P: $\mathrm{mm}(0.5)$ men det har gått bra $=$

$\mathrm{mm}(0.5)$ but it has gone well=

59. S: $=\mathrm{mm}($.$) men va skönt$

$=m m$ (.) but how nice

60. P: $[\mathrm{mm}]$

[mm]

61. S: [men] har det påverkat din (.) förståelse ((pekar i

62. en cirkelrörelse mot huvudet)) av tal någonting eller

63. är det bara ditt eget tal ((för handen framför munnen)) som

64. har påverkats (.) du har hela tiden kunna förstått vad

65. andra [har sagt]

[but] has this affected your (.) understanding ((points in a circular movement toward the head)) of speech in any way or is it only your own speech ((moves hand in front of the mouth)) that has been affected (.) you have been able to understand what other people have said [all along]

66. P:

[ ja: ]

[yes:]

67. S: det föll inte bort någonting?= nothing was lost?=

68. P: =eh (.) ne ((harklar)) när jag är trött (0.5) jag

69. lider av hjärntrötthet ((pekar mot huvudet))

$=$ eh (.) no ((clears throat)) when I am tired (0.5) I suffer from brain fatigue

((points to the head))

70. S: $\mathrm{mm}$

$m m$

71. P: och dä är ju: (0.5) när jag (.) då kan de va svårt

and that is (0.5) when I (.) then it can be difficult

72. S: $\mathrm{mm}(($ nickar $))$

$m m($ nods)) 
73. P: ehf:: ah (.) för mig (.) < orden> ((för handen framför

74. munnen)) liksom (.) faller bort

ehf: ah (.) for me (.) < the words $>(($ moves the hand in front of the mouth $))$ are lost

Excerpt 6 starts with the PWA talking about things that she could not do in the beginning after the stroke, but which she can do now (lines 56, 58). The student closes this sequence with a positive evaluation (line 59), and then asks a follow-up question formatted as a candidate understanding specifying the nature of P's aphasia (lines 61-65). This utterance is accompanied by two iconic gestures, possibly used to enhance P's understanding. This specification of the nature of the problems is confirmed by $\mathrm{P}$ (line 66), and further developed by the student (line 67). P confirms the previous statement but adds a comment about brain fatigue (lines 68-69), also accompanied by an indexing gesture. This description of her problems is elaborated (lines 71, 73-74), and this time $\mathrm{P}$ mimics the iconic gesture for word production previously used by $\mathrm{S}$.

\section{Excerpts illustrating content use}

The last excerpts of interest during this study comprise examples illustrating how students chose sequences where the PWAs talk about their aphasia and how it affects their daily living. This category was rather large, despite the fact that the students were instructed to choose examples illustrating interactional phenomena relevant for talking to persons with communicative disabilities.

Excerpt 7 is taken from a conversation between the student (S) and one of the participating PWAs $(\mathrm{P})$ a couple of minutes into the conversation. $\mathrm{P}$ is explaining to $S$ how it felt to wake up after a stroke, realizing that he had aphasia.

\section{Excerpt 7}

48. P: och då hade jag afasi

and then I had aphasia

49. S: hur kändes det då

how did that feel

50. förstod du då vad visste du vad det va did you understand what it was

51. P: nej alltså jag förstod ingenting eh eller alltså::

no, then I understood nothing eh or then::

52. när ja (0.2) jag pratade ju med folk when I (0.2) I talked to people

53. S: $[\mathrm{mh}](($ nickar $))$

[mh] ((nods))

54. P: [men eh] jag säger alltså (.) ((fram med handen))

[but eh] I say then (.) ((puts hand forward)) 
55. . .hh ja ja jag sa någonting ((visar med handen)) .hh yes yes I said something ((shows with his hand))

56. det låter som när jag pratar nu men de jag sa it sounds as when I talk now but what I said

57. siffrorna helt det står ju ba låter ba jiddel the numbers totally it says on sounds on gobbledy-

58. jabbel alltså de de blir bara (.) ((fram med händerna)) gook then it it only becomes (.) ((puts hands forward))

59. ingen förstod ju vad ${ }^{*}$ jag sa*

nobody understood what ${ }^{*}$ said ${ }^{*}$

In line 48, the PWA concludes that he got aphasia (this is the end of a previous sequence describing how he had his stroke, and ended up in hospital), and the student asks how that felt (lines 49-50). The PWA explains how it felt and what it sounded like, giving a good illustration of how aphasia diminishes the possibilities of participation in conversations, so he has to exercise his rights in different situations (lines 51-59). This excerpt also exemplifies a beneficial strategy, since the student supports the PWA's narrative through back-channeling and body language (line 53).

In the next excerpt (8), taken from the beginning of the conversation, the PWA (P) explains that she cannot speak English any longer. The student (S) confirms that she has understood that foreign languages may be difficult, and she also poses some clarifying questions.

\section{Excerpt 8}

1. P: men (.) ja ja eh ja kan inte ee: engelska [nu mera] but (.) yes yes eh I cannot e: english [anymore]

2. S: [neej precis] [no exactly]

3. aa det har [vi fått förstått] nu att det kan vara yea we have [had understood] now that it may be

4. P: $[\mathrm{mm}$ aa ]

5. S: svårt med [andra språk] difficult with [other languages]

6. P: [jaa: ] ((nickar)) [yes: ] ((nods))

7. S: även fast du kunde engelska [innan] even though you knew English [before]

8. P: [aa visst] jaa [yea of course] yes

9. S: jaa aa (.) å hur undra hur det skulle va om man va yes yea (.) and how wonder how it would be if one

10. tvåspråkig om man då tappar båda was bilingual if you lose both then 
In excerpt 8, the PWA states that she can no longer speak English (line 1), which is confirmed, and expanded on by the student (lines 2-3). The student continues by posing a clarifying question about the PWA's previous knowledge of English (line 5), which is answered by the PWA (line 6) and expanded by the student (line 7). This excerpt illustrates that different aspects of communication may be affected by aphasia, and that the student appears to have understood and internalized this insight.

In summary, excerpts $1-8$ are representative examples of sequences that were chosen by the students as relevant for discussion. The two teachers participating in this seminar (and also the article authors) acted as facilitators in the discussions and strove to let the students steer the discussions. In addition, the excerpts together with the discussions in the seminar demonstrate how the participation of PWAs in speech-language pathology education may enhance students' perception of the communicative problems experienced by PWAs, and how different interactional strategies may enhance or aggravate those problems.

\section{Interview}

The analysis of the focus-group interview indicated that the PWAs stated that they appreciated the student conversations in several different ways. First, they believed that they were able to disseminate important knowledge, both on aphasia in general, but also specifically regarding which strategies can be of support in conversations with PWAs and when. Second, they thought it important to show the students that aphasia has many faces, which may affect communication in different ways. Third, they reported that conversations with many unknown persons represented valuable training and also enhanced their communicative confidence. They all reported that it was hard to give feedback to the students, especially when they used less beneficial strategies. The PWAs also expressed that they found the activity rather tiring. However, the PWAs were all willing to continue with this communication partner scheme.

\section{Student evaluation}

A vast majority of the participating students (97\%) indicated that they had gained new insights about their own way of communicating through the exercise, and 94\% discovered new things about their own communication methods by studying the video recordings and making the transcriptions. Additionally, many of the participating students (60\%) mentioned gaining knowledge as to how aphasia affects communication and how different PWAs are affected. Additional insights gleaned from student retrospection provided greater awareness of their own interactional formulations, speech tempo, 
clarity, listening skills, and body language. The discovery of enhancing strategies is illustrated by the following responses:

Jag kunde tydligt se mina reparationer [My repairs were clear to me]

Jag gav mycket bekräftelse [I gave many back-channeling signals]

Examples of comments about less beneficial strategies included:

Jag måste tala långsammare och tydligare [I really need to speak more slowly and clearly]

Jag avbryter ofta och fyller i [I interrupt and fill in too much]

\section{Discussion}

This study shows that student engagement in this variant of a communication partner scheme, with filming of the conversations, making transcriptions and analyses of the conversation according to conversation analytical conventions and principles, and reflecting on their recordings by observation, provided important knowledge to the students both on how aphasia may affect and limit PWAs' communicative activity and participation. Additionally, handson insights as to how different interactional strategies may enhance PWAs' effectiveness or contribute to ineffectiveness in interaction were made evident to the participating students. Some of these results were also shown in the study by Finch and colleagues (2017), where measurable enhancing strategies in conversations with PWAs could be obtained after only one lecture on strategy identification and usage.

Efficient communicative participation for PWAs in everyday social interaction is premised on trained communication partners (Cherney et al., 2013; Eriksson, 2015). By engaging PWAs in early stages of SLP education, students become aware of how their own contributions in conversation have an impact on mutual understanding. The increased awareness may possibly also be of general benefit to students when entering clinical practice further into the educational program. Students were able to identify both beneficial and less beneficial strategies, but they also found that topicalizing interactional phenomena enhanced their understanding of communicative impairments. Specific strategies that may enhance PWAs' possibilities for participating when used by conversational partners were demonstrated, and the collaborative nature of interaction was revealed to students, something which was also made clear in the seminar after the meetings between PWAs and students.

The participating students were at the very beginning of their speech and language pathology education, and they had no previous knowledge of aphasia and aphasia intervention, and no training in clinical communication skills. 
Since in most SLP programs, clinical interaction and effective communication is taught to students as important components of their professional roles, and is scheduled into the different courses dealing with different communication disorders, the choice of implementing the communication partner exercise during the first study year was deliberate. During such pedagogical exercises, the students' focus could be directed toward communication in general, and more specifically on elements in the communication that facilitated or hindered the interaction. Through this first step in becoming skilled communication partners, they are better prepared to acquire later expertise regarding aphasia intervention, with its growing focus on communicative participation in family as well as community contexts (Horton, Lane, and Shiggins, 2016).

The PWAs as experts believed that they played an important role in the mediation of this knowledge. This is in accordance with the social model of disability used in aphasiology where PWAs are considered to be experts in their own condition (Byng and Felson Duchan, 2005). This was also shown in the study by McVicker and co-workers (2008), where the PWAs reported a positive change in confidence, and that the project gave them a chance to talk. The expert role assigned to the participating PWAs may also be considered crucial, since by letting students share in their experiences in a systematic way, they also contributed to increasing the students' skills as communication partners, which is an important part of a communication partner training program.

\section{Conclusions and future directions}

In evaluations of both students and PWAs, it was found that the exercise was important and rewarding. It would be interesting to repeat the exercise later in the program, and also to let the students make comparisons between recordings and transcripts from the first and subsequent conversations. This learning activity could also be relevant for other health-care education programs.

\section{Acknowledgments}

The authors are deeply grateful to the participating PWAs and students. This research was partially financed by a pedagogical grant from Linköping University.

Declarations of interest: the authors certify that they have no affiliations with or involvement in any organization or entity with any financial interest in the subject matter or materials discussed in this article. 


\section{About the authors}

Inger Lundeborg Hammarström is associate professor at the Division of Speech Language Pathology, Audiology and Otho-Rhino-Laryngology, Linköping University. She has worked on speech and language disorders in children and adults both clinically and in education.

Christina Samuelsson is professor at the Division of Speech Language Pathology, Department of Clinical Science, Intervention and Technology, CLINTEC, Karolinska Institute. She has worked on language disorders in children and adults, especially from an interactional perspective. She has also a particular interest in the use of video recording and interactional analysis in educational and clinical settings.

\section{References}

Antaki, C. (2011). Applied Conversation Analysis. Basingstoke: Palgrave-Macmillan. https:// doi.org/10.1057/9780230316874

Basso, A. (2003). Aphasia and its Therapy 49-74. New York: Oxford University Press.

Byng, S., and Felson Duchan, J. (2005). Social model philosophies and principles: Their application to therapies for aphasia. Aphasiology, 19(10-11), 906-922. https://doi. org/10.1080/02687030544000128

Cherney, L. R., Simmons-Mackie, N., Raymer, A., Armstrong, E., and Holland, A. (2013). Systematic review of communication partner training in aphasia: Methodological quality. International Journal of Speech-Language Pathology, 15(5), 535-545. https://doi.org/ $\underline{10.3109 / 17549507.2013 .763289}$

Chui, K. (2014). Mimicked gestures and the joint construction of meaning in conversation. Journal of Pragmatics, 70, 68-85. https://doi.org/10.1016/j.pragma.2014.06.005

Drew, P. (1998). An exercise in the comparative analysis of talk-in-interaction in different (institutional) settings: The case of formulations. In H. Lehti-Eklund (Ed.), Samtalsstudier 29-42. Helsinki: University of Helsinki.

Eriksson, K. (2015). The supporting conversation partner in disordered communication. $\mathrm{PhD}$ dissertation, Gothenburg University, Gothenburg, Sweden.

Finch, E., Cameron, A., Fleming, J., Lethean, J., Hudson, K., and McPhail, S. (2017). Does communication partner training improve the conversation skills of speech-language pathology students when interacting with people with aphasia? Journal of Communication Disorders, 68, 1-9. https://doi.org/10.1016/j.jcomdis.2017.05.004

Goodwin, C. A. (2004). Competent speaker who can't speak: The social life of aphasia. Journal of Linguistic Anthropology, 14(2), 151-170. https://doi.org/10.1525/ jlin.2004.14.2.151

Heritage, J. (1985). Analyzing news interviews: Aspects of the production of talk for an overhearing audience. In T. A. van Dijk (Ed.), Handbook of Discourse Analysis - Discourse and Dialogue (3rd ed., pp. 95-117). London: Academic Press Inc.

Horton, S., Lane, K., and Shiggins, C. (2016) Supporting communication for people with aphasia in stroke rehabilitation: transfer of training in a multidisciplinary stroke team. Aphasiology, 30(5), 629-656. https://doi.org/10.1080/02687038.2014.1000819 
Hutchby, I., and Wooffitt, R. (2008). Conversation Analysis (2nd ed.). Cambridge: Polity. Intercollegiate Stroke Working Party (2012). National Clinical Guidelines for Stroke (4th ed.). London: Royal College of Physicians.

Kagan, A., and LeBlanc, K. (2002). Motivating for infrastructure change: Toward a communicatively accessible, participation-based stroke care system for all those affected by aphasia. Journal of Communication Disorders, 35(2), 153-169. https://doi.org/10.1016/ $\underline{\text { S0021-9924(02)00062-X }}$

Kagan, A., Black, S., Duchan, J., Simmons-Mackie N., and Square, P. (2001). Training volunteers as conversation partners using 'supported conversation for adults with aphasia (SCA)': A controlled trial. Journal of Speech, Language \& Hearing Research, 44, 624-638. https://doi.org/10.1044/1092-4388(2001/051)

Kendon, A. (2004). Gesture: Visible Action as Utterance. Cambridge: Cambridge University Press. https://doi.org/10.1075/gest.4.1.07ken

Kurhila, S. (2003). Co-constructing understanding in second language conversation. Dissertation, University of Helsinki, Finland.

McVicker, S., Parr, S., Pound, C., and Duchan, J. (2009). The Communication Partner Scheme: A project to develop long-term, low-cost access to conversation for people living with aphasia. Aphasiology, 23, 52-71. https://doi.org/10.1080/02687030701688783

Plejert, C., Samuelsson, C., and Anward, J. (2016). Enhanced patient involvement in Swedish aphasia intervention. Clinical Linguistics \& Phonetics, 30(10), 730-748. https:// doi.org/10.1080/02699206.2016.1208274

Sacks, H., Schegloff, E. A., and Jefferson, G. (1974). A simplest systematics for the organization of turn taking for conversation. Language, 50(4), 696-735.

Schegloff, E. A., Jefferson, G., and Sacks, H. (1977). The preference for self-correction in the organization of repair in conversation. Language, 53(2), 361-382. https://doi. org/10.1353/lan.1977.0041

Sekine, K., and Rose, M. L. (2013). The relationship of aphasia type and gesture production in people with aphasia. American Journal of Speech-Language Pathology, 22(4), 662-672. https://doi.org/10.1044/1058-0360(2013/12-0030)

Sidnell, J. (2012). Basic conversation analytic concepts. In J. Sidnell and T. Stivers (Eds.), The Handbook of Conversation Analysis: An Introduction 77-101. Chichester: WileyBlackwell. https://doi.org/10.1002/9781118325001.ch5

Thrift, A. G., Thayabaranathan, T., Howard, G. Howard, V. J., Rothwell, P. M., Fegin, V. L., Norrving, B., Donnan, G. A., and Cadilhac, D. A. (2017). Global stroke statistics. International Journal of Stroke, 12(1), 13-32. https://doi.org/10.1177/17474993016676285

Wallace, S. J., Worrall, L., Rose, T., and Le Dorze, G. (2017a). Which treatment outcomes are most important to aphasia clinicians and managers? An international e-Delphi consensus study. Aphasiology, 31(6), 643-673. https://doi.org/10.1080/02687038.2016.1186 $\underline{265}$

Wallace, S. J., Worrall, L., Rose, T., Le Dorze, G., Cruice, M., Isaksen, J., and Gauvreau, C. A. (2017b). Which outcomes are most important to people with aphasia and their families? An international nominal group technique study framed within the ICF. Disability and Rehabilitation, 12, 1-10. https://doi.org/10.1080/09638288.2017.1400593 


\section{Appendix 1: Transcription conventions}

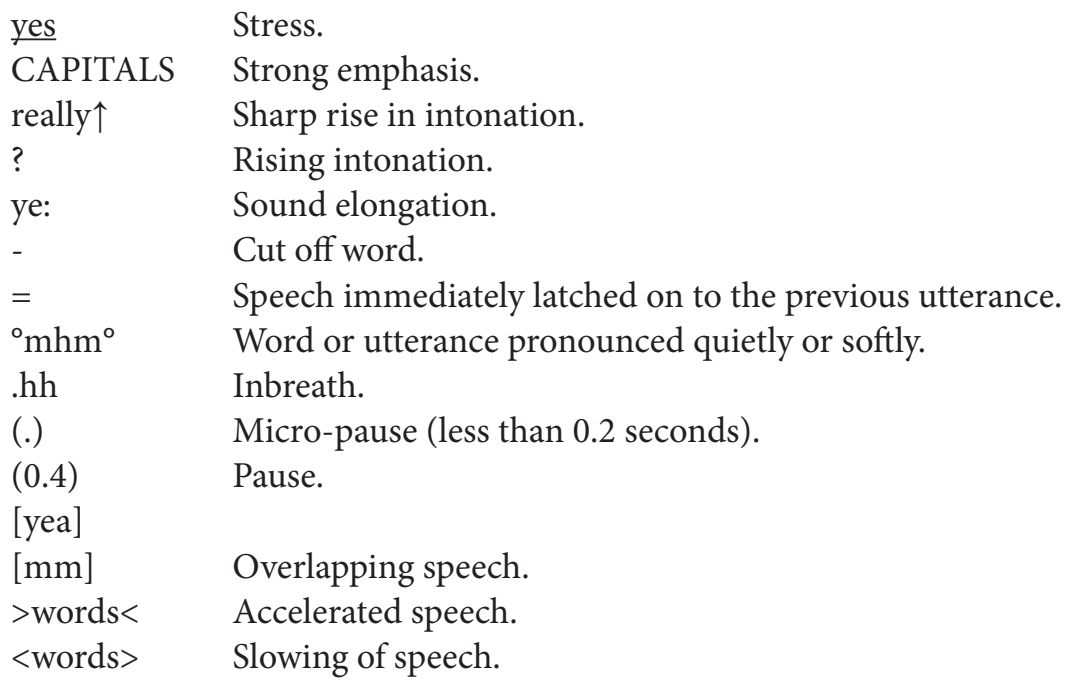

\section{Appendix 2. Interview guide for the focus group interview}

Topics:

1. Personal experience.

2. The students' experience.

3. Difficulties.

4. New insights about own communication.

5. How was feedback given?

6. To think about for continuation of the project. 